
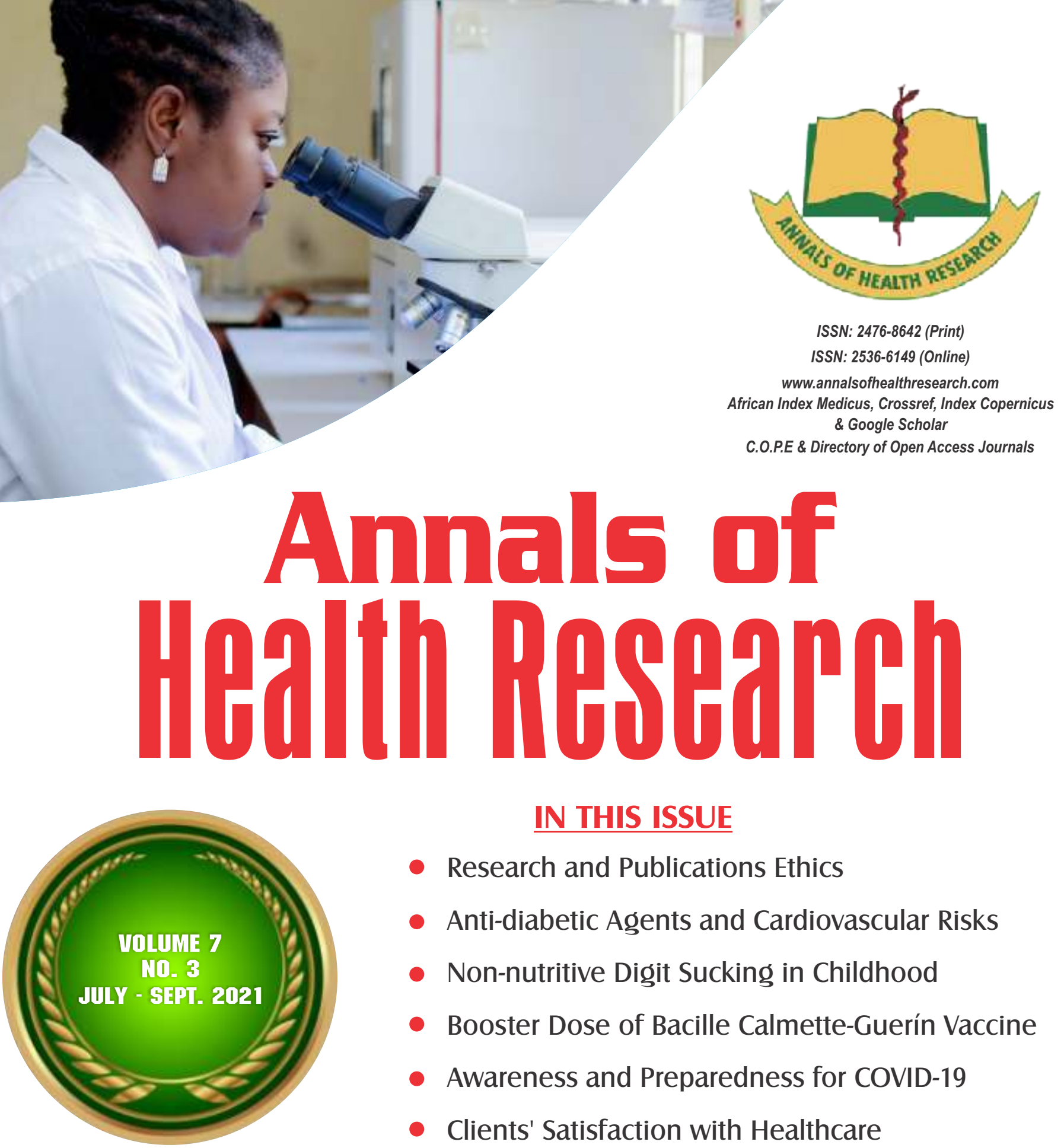

IN THIS ISSUE

- Research and Publications Ethics

- Anti-diabetic Agents and Cardiovascular Risks

- Non-nutritive Digit Sucking in Childhood

- Booster Dose of Bacille Calmette-Guerín Vaccine

- Awareness and Preparedness for COVID-19

- Clients' Satisfaction with Healthcare

- Antimicrobial Activity of Lactic Acid Bacteria

- Saddle Block for Transrectal Prostate Biopsy

- Physical and Mental Health of Stroke Survivors

- Transfusion Transmissible Infections

- Cervical Ectopic Pregnancy

PUBLISHED BY THE MEDICAL

AND DENTAL CONSULTANTS ASSOCIATION

OF NIGERIA, OOUTH, SAGAMU, NIGERIA.

www.mdcan.oouth.org.ng 


\title{
Assessment of the Antimicrobial Activity of Lactic Acid Bacteria from Sorghum Slurry on Clinical Strains of Diarrhoeagenic Escherichia coli
} Okunye $\mathrm{OL}^{* 1}$, Okanlawon $\mathrm{BM}^{2}$, Idowu $\mathrm{PA}^{3}$, Adeleye $\mathrm{O}^{4}$, Fasuyi $\mathrm{OC}^{5}$ ${ }^{1}$ Department of Pharmaceutical Microbiology, Faculty of Pharmacy, Olabisi Onabanjo University, Ogun State, Nigeria ${ }^{2}$ Department of Medical Laboratory Science, College of Health Sciences, Ladoke Akintola University of Technology, Ogbomosho, Nigeria

3Department of Pharmaceutical Microbiology, Faculty of Pharmacy, University of Ibadan, Ibadan, Nigeria 4Department of Pharmaceutics, Faculty of Pharmacy, Federal University, Oye Ekiti, Nigeria ${ }^{5}$ Department of Microbiology, College of Biological Sciences, Federal University of Agriculture, Abeokuta, Ogun State, Nigeria

*Correspondence: Dr OL Okunye, Department of Pharmaceutical Microbiology, Faculty of Pharmacy, Olabisi Onabanjo University, Ogun State, Nigeria. E-mail: femfem111@yahoo.com; ORCID - https://orcid.org/0000-0001-6444-563X.

\begin{abstract}
Background: Sorghum is a nutrient-rich grain ground into flour to make different types of delicacies, and it has been reported to possess probiotic potentials.

Objective: To assess the antimicrobial activity of Lactobacillus plantarum obtained from sorghum slurry on strains of enteropathogenic Escherichia coli from cases of diarrhoea.

Methods: A total of 36 samples of wet-milled sorghum slurry and liquor $\mathrm{pH}$ were obtained and cultured on MRSA and were, after that, biochemically characterized for Lactobacillus plantarum, which was tested by agar well diffusion against 15 strains of Escherichia coli isolated from cases of diarrhoea.

Results: Microbiological analysis of the 36 samples of sorghum explored produced 15 isolates of Lactobacillus plantarum. A progressive increase in acidity in relation to an increase in the period of fermentation was observed. Ninety-five per cent of the Escherichia coli strains showed resistance against some standard antibiotics. At the same time, the isolates of Lactobacillus plantarum obtained inhibited isolates of diarrhoeagenic Escherichia coli tested, showing potential usefulness of the sorghum slurry as a probiotic.

Conclusion: The inhibitory activity of Lactobacillus plantarum isolated from sorghum slurry showed antimicrobial potentials that could be used for therapeutic purposes in treating diarrhoea caused by Escherichia coli, pending further investigation.
\end{abstract}

Keywords: Antibacterial activity, Diarrhoeagenic Escherichia coli, Lactic acid bacteria, Lactobacillus plantarum, Sorghum slurry.

\section{Introduction}

Lactic acid bacteria constitute a heterogeneous group of non-sporulating, Gram-positive, catalase-negative, anaerobic, microaerophilic, aerotolerant rods or cocci that produce lactic acid as the sole product from energy-yielding fermentation of sugar. The lactic acid bacterial species with the potential to initiate homo- or 
hetero- fermentation include Lactobacillus fermentum, Lactobacillus plantarum, Lactobacillus salivarius, Lactobacillus delbruekii, Lactobacillus amylolyticus, Lactobacillus reuteri, Lactobacillus paraplantarum, Lactococcus lactis, Leuconostoc mesenteroides, Pedicoccus acidilactici, Pediococci pentaceous, Streptococcus gallolyticus and Weissella confusa and they have been reported to possess probiotic potential. [1]

Fermented foods constitute a significant component of the African diet. [2] Fermentation occurs using natural microflora, or starter culture obtained in beer, wine, bread, and yoghurt. In natural fermentation, the conditions are so set that the desirable microorganisms grow preferentially and produce metabolic byproducts, giving the product's unique characteristics.

Starter cultures are added to the raw materials in large numbers and incubated under optimal conditions. In everyday controlled fermentation, starter culture bacteria produce yoghurt, sauerkraut, and lactic acid products. These products prevent the growth of undesirable microorganisms in the non-sterile raw material and help make the product shelf-stable. Lactic acid fermentation enhances the shelf-life of the fermentation product, most likely because of the diverse array of antimicrobial metabolites produced during the fermentation process. Lactic acid bacteria (LAB) are the primary microorganisms used to ferment maize, sorghum or millet-based foods processed in West Africa. Fermentation is natural but must involve mixed cultures of lactic acid bacteria (LAB), yeasts and fungi. $\mathrm{LAB}$ can produce a range of other antimicrobial metabolites, including ethanol generated via the glycolytic pathway, hydrogen peroxide produced during aerobic growth, diacetyl formed from excess citrate-derived pyruvate and bacteriocins, which are ribosomally synthesized antimicrobial compounds. [3, 4].
Among the various fermentation processes in Africa, lactic acid fermentation is one of the oldest and most widespread. Fermentation contributes to desirable changes in taste, flavour, acidity, digestibility and texture in gruels (sorghum, baca, dalaki), doughs (agidi, banku, kome) or steam-cooked granulated products (arraw, ciacry, degue). Food preservation by lactic acid fermentation relies on removing fermentable carbohydrates, the consumption of oxygen, the formation of organic acids and a concomitant decrease in $\mathrm{pH}$. [5]

The immediate and rapid production of sufficient quantities of organic acids to reduce $\mathrm{pH}$ below 4.0 within 24 hours of fermentation is an essential requirement of fermented cereal-based foods. The rapid production of these compounds may contribute to the inhibition of pathogenic or spoilage flora and thus, enhance the shelf-life and microbial safety of the fermented product. [6, 7] The consumption of fermented foods has significantly increased in industrialized nations since the 1970s, embracing common foods like yoghurt, butter, milk, fermented soy source, and sausages. [8] One of the likely reasons for the increase in the consumption of fermented foods is their probiotic component. A "probiotic" is a live microbial feed supplement that beneficially affects the host animal by improving its intestinal microbial balance. The major consumption of probiotics by humans is in the form of fermented foods such as dairy products or from the ingestion of freeze-dried organisms. Consumption of probiotics affects the composition of the intestinal microflora, thereby impacting some beneficial effects on the consumer. To observe a positive health benefit from the consumption, a minimum dose required for health benefit is usually $10^{9}-10^{11} \mathrm{CFU} /$ day. [9]

Probiotic assessment of LAB embraces their potential capability to influence local metabolic activities: for example, stimulating intestinal mucosal lactase activities, which can prevent 
some types of diarrhoea, stimulation of the immune system, and anti-carcinogenic activity. Probiotic microbes are host-specific. Thus a strain selected as a probiotic in one animal may not be suitable in another species. Microbes selected for probiotic use should exhibit the following characteristics: adherence to the intestinal mucosa of the host, be easily cultured, be nonpathogenic and non-toxic to the host, exert a beneficial effect on the host, remain viable for a long time, produce beneficial enzymes or physiological end-products that the host can use and withstand acidic condition in the host stomach and bile salts in the small intestine. [10]

Sorghum (Sorghum bicolour (L) Moench), locally called guinea corn, is the most extensively grown cereal grain in Africa and Asia. [11]. The crop is environmentally friendly as it is water-efficient, requires little or no fertilizers or pesticides and is biodegradable. Sorghum is a nutrient-rich grain that may be ground into flour to make bread, porridge, and pancakes. It is a non-Genetically Modified Organism, gluten-free, ancient grain mainly used as feed for livestock. Still, it is also a popular food grain for humans residing in Asia and Africa. Due to its gluten-free nature, sorghum is a useful whole-grain alternative for gluten intolerance or celiac disease. In Nigeria's Savanna and semi-arid regions, millions of people consume sorghum in their daily diets as staple foods. These foods are high in energy and other nutrients and are recommended for infants, pregnant and lactating mothers, the elderly, and the convalescent. [12]

Escherichia coli is a prominent member of the indigenous flora of the human intestinal tract and a major aetiologic agent of gastroenteritis. However, some strains of Escherichia coli may cause diseases of the gastrointestinal and urinary tracts or central nervous system in human hosts. Gastroenteritis caused by Escherichia coli ranges from mild diarrhoea to a more severe form with debilitating loss of fluids and electrolytes.
Enterohaemorrhagic E. coli serotype $\mathrm{O} 157$ is a pathotype of diarrhoeagenic strains with a large virulence plasmid pO157 which produces one or more Shiga-like toxins. They produce biogenic amines considered responsible for dangerous systemic intoxication. Diarrhoeagenic strains of Escherichia coli can be divided into at least six different types with corresponding distinct pathogenic schemes. These organisms probably represent the most common cause of paediatric diarrhoea worldwide. Several specific clinical syndromes accompany infection with diarrhoeagenic Escherichia coli, including traveller's diarrhoea (enterotoxigenic Escherichia coli), haemorrhagic colitis and haemolytic uraemic syndrome (enterohaemorrhagic Escherichia coli), persistent diarrhoea (enteroaggregative Escherichia coli), and watery diarrhoea of infants (enteropathogenic Escherichia coli). [13]

This study was designed to assess the antimicrobial activity of Lactobacillus plantarum obtained from sorghum slurry on strains of enteropathogenic Escherichia coli from cases of diarrhoea to suggest the organism as a probiotic.

\section{Methods}

\section{Collection of raw materials}

The research team purchased sorghum (Sorghum bicolour (L) Moench) from different market locations in Ibadan, Oyo State, Nigeria. The samples were kept in sterilized plastic bags and stored at $25-28^{\circ} \mathrm{C}$ for further use.

\section{Collection of Escherichia coli isolates}

Clinical isolates of Escherichia coli from cases of diarrhoea were collected from the pharmaceutical microbiology laboratory of the Department of Pharmaceutical Microbiology, University of Ibadan. These were further characterized by sub-culturing on Eosin Methylene Blue (EMB) and conventional 
biochemical tests, including indole, methyl red, catalase, and Voges Proskauer, glucose fermentation and oxidase test.

\section{Fermentation of Sorghum}

Fermentation of sorghum was carried out by simulating the traditional method of processing. The grains were soaked in boiled water and allowed to ferment for 48 hours. The softened grains were washed, wet-milled and sieved. The wet-milled sorghum was covered and left to ferment at $25-28^{\circ} \mathrm{C}$. The slurry and liquor samples were aseptically withdrawn during fermentation at intervals: day 1 , day 2 , and day 3 for $\mathrm{pH}$ determination and microbiological analysis.

\section{pH Measurement}

The $\mathrm{pH}$ during fermentation was measured using a $\mathrm{pH}$ meter, model 7020. The $\mathrm{pH}$ meter was calibrated using standard buffer solutions (Merck) at $\mathrm{pH} 4.0$ and 7.0.

\section{Isolation of $L A B$}

To form a concentrated pulp, one gram of sorghum slurry was homogenized in $9 \mathrm{~mL}$ of sterile, distilled water. Volumes of $1.0 \mathrm{ml}$ and $0.1 \mathrm{ml}$, of $10^{-5}$ and $10^{-6}$ dilutions, respectively, were plated out by mixing with MRS agar medium in McCartney bottles and poured aseptically into sterile culture plates. The plates were swirled for even distribution of inoculum and setting of agar medium. The plates were then incubated under microaerophilic conditions for 72 hours, and the colonies of bacterial growth were randomly selected after incubation. The selected isolates were sub-cultured, and repeated streaking was done on MRS plates to obtain pure cultures. The isolates were stored at $-20^{\circ} \mathrm{C}$ for further use.

\section{Viable count of Lactobacillus plantarum}

Ten-fold serial dilution was done for all the samples up to $10^{-5}$. They were plated out on MRS agar and similarly incubated. The total LAB count was determined during the process of fermentation.

\section{Identification of Isolates}

Overnight culture of each isolate in MRS broth $\left(\right.$ Oxoid $\left.^{\circledR}\right)$ was tested for Gram reaction, catalase enzyme and production of acid from glucose, oxidation, or fermentation reaction. Only Grampositive bacteria with catalase-negative reactions were observed, and the representative isolates were purified by successive streaking onto MRS agar. ${ }^{[14]}$ Cultures grown for twenty-four hours were used for the biochemical tests.

\section{Antibacterial activity of Lactobacillus plantarum Agar well diffusion method}

The antimicrobial activity of LAB isolates selected based on preliminary findings was determined by cell-free supernatant assay against diarrhoeagenic E. coli. Lactobacillus plantarum isolates were grown in MRS broth at $37^{\circ} \mathrm{C}$ for 24 hours and centrifuged at $12,000 \mathrm{rpm}$ for 10 minutes. An aliquot of $100 \mu \mathrm{L}$ of the cellfree supernatant of the LAB was placed in a $6 \mathrm{~mm}$ well in Mueller Hinton agar seeded with approximately $0.5 \mathrm{McF}$ arland standard of the test pathogens using a micropipette. The cell-free supernatant was left to diffuse for 1 hour at 25$28^{\circ} \mathrm{C}$ before incubation at $37{ }^{\circ} \mathrm{C}$ for 24 hours. After that, the zones of growth inhibition observed were measured and recorded.

\section{Antibiogram of Escherichia coli isolates Determination of Antibiogram}

Antimicrobial susceptibility patterns of the isolates were determined using the modified Kirby Bauer agar diffusion method. Three to five colonies of the overnight grown strains were inoculated into a tube containing Tryptone Soy Broth and incubated overnight at $37^{\circ} \mathrm{C}$. Standardization of the inoculum was performed by diluting the broth cultures until turbidity matched the 0.5 McFarland standard. A sterile cotton wool swab was dipped into the 
standardized suspension, drained, and used for inoculating Mueller Hinton agar (Oxoid, UK) on a 100-mm culture plate.
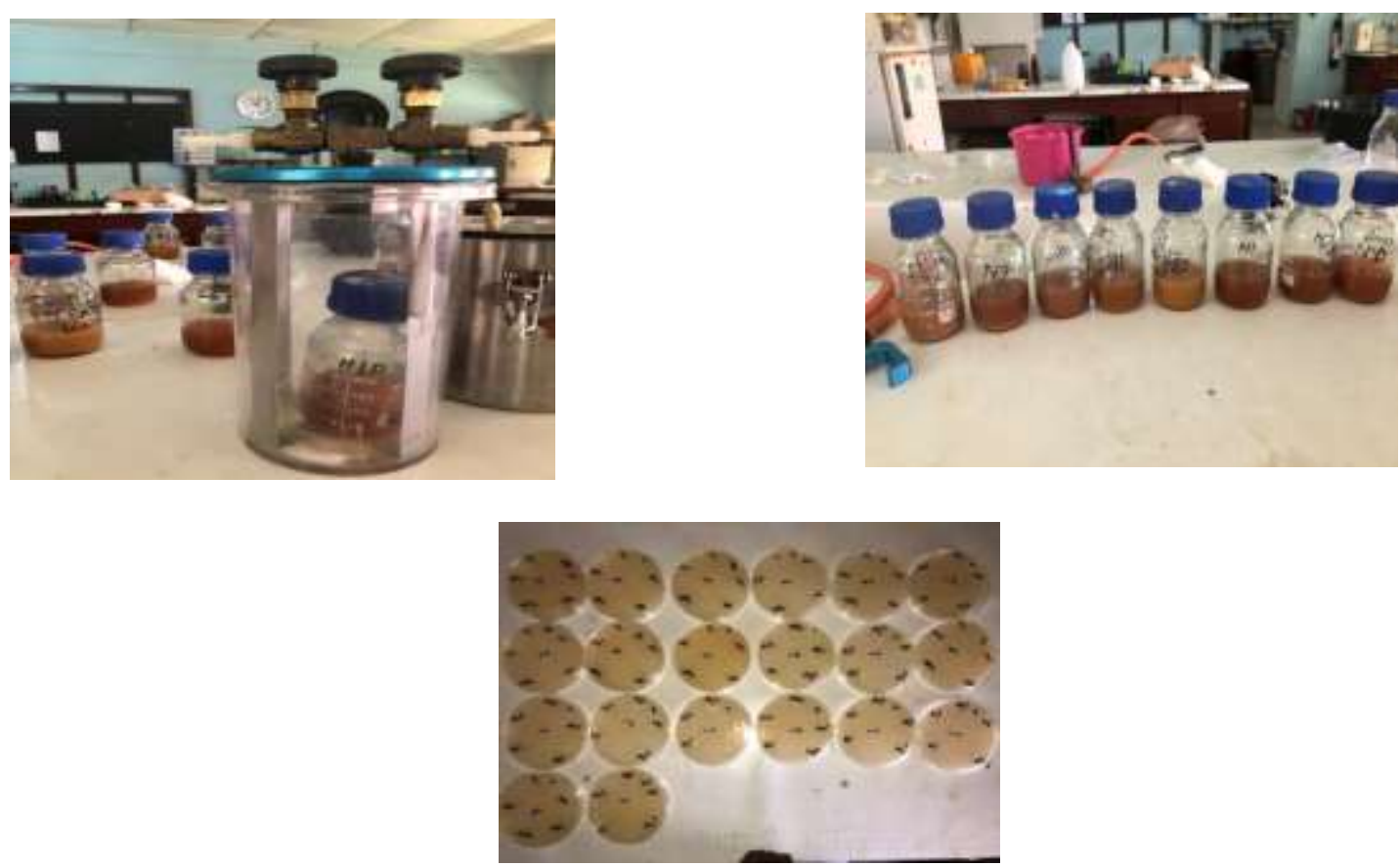

Figure 1: Microaerophilic incubator jar with culture plates, specimen bottle with MRS broth and pre-incubated culture plates.

The inoculated plates were air-dried for 30 minutes, and antibiotic discs were placed on the agar medium using flamed pair of forceps. They were gently pressed down to ensure maximum contact. Discs containing the following antibiotics were used: augmentin $(30 \mu \mathrm{g})$,

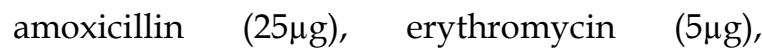
tetracycline $(10 \mu \mathrm{g})$, cloxacillin $(5 \mu \mathrm{g})$, cotrimoxazole $(25 \mu \mathrm{g})$, chloramphenicol $(30 \mu \mathrm{g})$, gentamicin $(10 \mu \mathrm{g})$ and ciprofloxacin $(5 \mu \mathrm{g})$. The plates were incubated aerobically at $37^{\circ} \mathrm{C}$ for 24 hours before measuring the diameters of zones of growth inhibition observed. Sensitive and resistant strains were marked $\mathrm{S}$ and $\mathrm{R}$ respectively as standardized by Clinical Laboratory Standard Institute. [14]

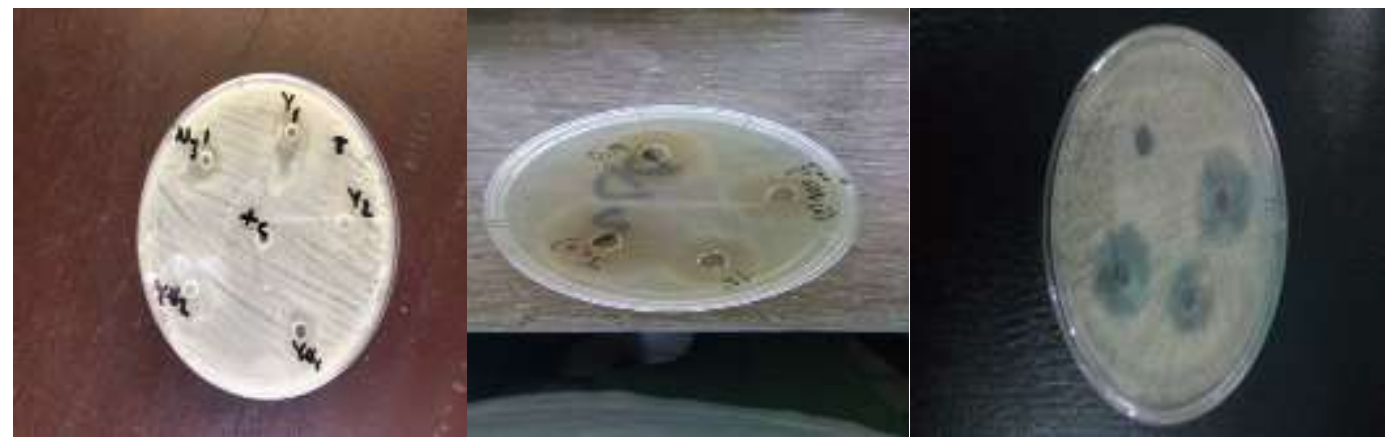

Figure 2: Selected culture plates of the isolates of Lactobacillus plantarum with their zones of growth inhibitions on tested isolates of Escherichia coli that were resistant to standard antibiotics. 


\section{Results}

Viability of Lactobacillus plantarum in sorghum slurry and liquor

Thirty-six samples of wet-milled sorghum (12 samples each for three sets of the tests) were fermented and observed for fermentation changes within 72 hours, as shown in Tables I, II and III. Progressive increases in acidity were observed as the hours of fermentation advanced.

Table I: $\mathrm{pH}$ changes relative to fermentation (Batch 1)

\begin{tabular}{lcll}
\hline Days & $\begin{array}{c}\text { Number of } \\
\text { samples }\end{array}$ & $\begin{array}{l}\text { Sorghum slurry } \\
\text { pH } \\
\text { Mean } \pm S D\end{array}$ & $\begin{array}{l}\text { Sorghum liquor } \\
\text { pH } \\
\text { Mean } \pm S D\end{array}$ \\
\hline 1 & 4 & $4.5 \pm 0.22$ & $5.8 \pm 0.14$ \\
2 & 4 & $4.2 \pm 0.24$ & $1.53 \pm 1.64$ \\
3 & 4 & $2.0 \pm 1.84$ & $1.46 . \pm 1.41$ \\
\hline
\end{tabular}

Table II: pH changes relative to fermentation (Batch 2)

\begin{tabular}{llll}
\hline Days & $\begin{array}{l}\text { Number of } \\
\text { samples }\end{array}$ & $\begin{array}{l}\text { Sorghum slurry } \\
\text { pH } \\
\text { Mean } \pm S D\end{array}$ & $\begin{array}{l}\text { Sorghum liquor } p H \\
\text { Mean } \pm S D\end{array}$ \\
\hline 1 & 4 & $5.4 \pm 0.14$ & $5.5 \pm 0.11$ \\
2 & 4 & $1.47 \pm 0.26$ & $4.37 \pm 1.42$ \\
3 & 4 & $1.99 \pm 0.22$ & $3.24 \times \pm 0.28$ \\
\hline
\end{tabular}

Table III: pH changes relative to fermentation (Batch 3)

\begin{tabular}{lcll}
\hline Days & $\begin{array}{c}\text { Number } \\
\text { of samples }\end{array}$ & $\begin{array}{l}\text { Sorghum slurry } \\
\text { pH } \\
\text { Mean } \pm S D\end{array}$ & $\begin{array}{l}\text { Sorghum liquor } p H \\
\text { Mean } \pm S D\end{array}$ \\
\hline 1 & 4 & $5.5 \pm 0.28$ & $4.52 \pm 0.22$ \\
2 & 4 & $3.47 \pm 0.16$ & $4.87 \pm 0.32$ \\
3 & 4 & $1.99 \pm 1.44$ & $3.14 \pm 1.12$ \\
\hline
\end{tabular}

Table IV depicts the biochemical characterization of the 15 isolates of the 36 samples identified to be Lactobacillus plantarum.

In Figure 3, the antibiogram of Escherichia coli shows that the organism was most remarkably susceptible to ofloxacin but highly resistant to ciprofloxacin, amoxicillin, gentamycin tetracycline and cotrimoxazole.

\section{Discussion}

Sorghum, a cereal delicacy that could be prepared in different forms, constitutes a significant percentage of the Nigerian diet. Its lactobacillus content is of probiotic and nutraceutical importance. All the isolates obtained from sorghum used in this study were identified and characterized. 
Table 4: Biochemical characterization of the isolates of Lactobacillus plantarum

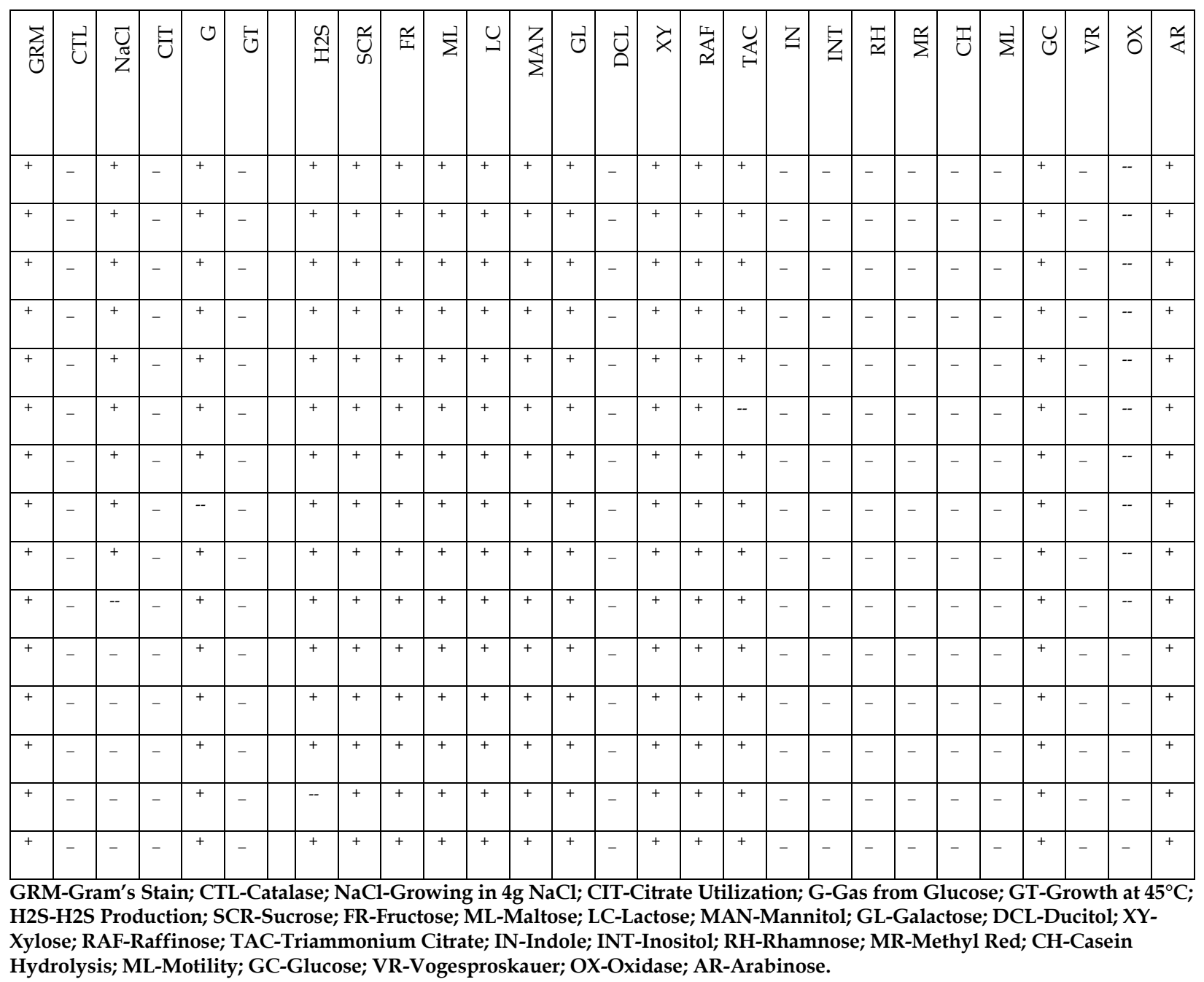

The isolates of Lactobacillus plantarum obtained were Gram-positive, catalase-negative, methyl red-negative, indole-negative but sucrose, maltose, and lactose positive. The cultural and biochemical properties of the isolates agreed with the report of George-Okafor and Anosike on fermented corn waste liquor as a potential source for probiotic lactic acid bacteria. ${ }^{[14]}$ The species of lactobacilli isolated was Lactobacillus plantarum. The isolation frequency could be due to the anaerobic nature of the product that permits organisms to tolerate this anaerobic condition.

The $\mathrm{pH}$ of the sorghum slurry and liquor decreased with the increasing duration of fermentation. The observed average decrease in $\mathrm{pH}$ from 4.5 to 2.0 and from 5.8 to 1.46 as observed in the first three days of the fermentation of the first batch, from 5.4 to 1.99 and 5.5 to 3.24 , and from 5.5 to 1.99 and 4.52 to 3.14 in the repeated second and third batches of the slurry and liquor respectively to confirm the viability of the sorghum could be attributed to the metabolic activity of these acidophilic organisms concerning fermentation which contributed to a gradual decrease in acidity as the organisms lagged out from metabolic exhaustion. This corroborated the findings of Vrese and Marteau on the effects of probiotic and prebiotic supplements on diarrhoea. ${ }^{[15]}$ 


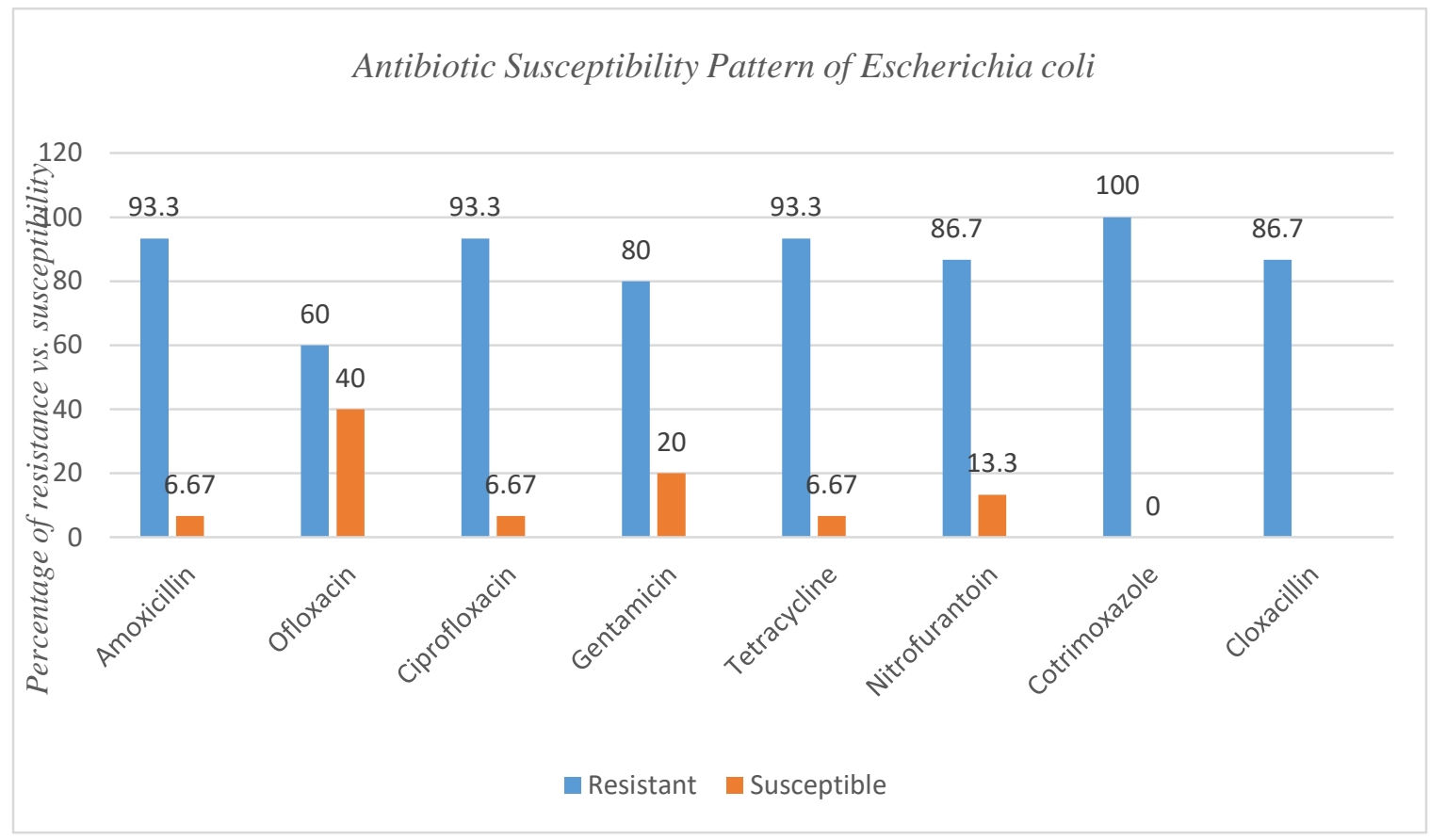

Figure 3: Antibiogram of Escherichia coli

The antibiotic susceptibility of diarrhoeagenic isolates of Escherichia coli showed that $93.3 \%$ were resistant to amoxicillin, ciprofloxacin and tetracycline. The isolates were $86.7 \%$ resistant to nitrofurantoin, cloxacillin, $60 \%$ resistant to ofloxacin and $100 \%$ resistant to cotrimoxazole. The widespread resistance profile of this organism could be attributed to unguided use of antibiotics, transformation between closely related pathogens, chromosomal mediated resistance or exchange of multidrug resistance gene on plasmid during conjugation. This corroborated the findings of David and Famurewa on prophylactic and bio-therapeutic benefits of 'ogi' - a lactic acid fermented maize slurry. [15] Most of the Lactobacillus plantarum isolated and tested against selected isolates of diarrhoeagenic Escherichia coli in the present study showed bacteriostatic activity, as evident in the zones of growth inhibition recorded against the Escherichia coli isolates. The bacteriostatic activity exhibited by Lactobacillus plantarum could be attributed to the metabolites produced by the organism with the potentials for being immune-friendly, in agreement with the reports of Ojo et al., on the evaluation of the viability of lactic acid bacteria in a Nigerian commercial yoghurt. [16]

Lactic acid bacterial antagonism could be attributed to the production of organic acids, ethanol, diacetyl, hydrogen peroxide or carbon dioxide, alone or in combination. It could further result from the production of bacteriocins. Pal and Ramana [17] reported inhibiting Escherichia coli and Staphylococcus aureus species during sorghum fermentation by bacteriocin-producing Lactobacillus. Various findings have been reported on the antagonistic activity of LAB from dairy products against diarrhoea infection. Still, there is a shortage of information on the antimicrobial-producing lactic acid bacteria isolated from sorghum in Nigeria against diarrhoeagenic Escherichia coli. [17] 


\section{Conclusion}

Isolates of Escherichia coli that elicited resistance in varying degrees to conventional antibiotics were sensitive to larger numbers of Lactobacillus plantarum antimicrobial activity in this study. Therefore, Lactobacillus plantarum has probiotic potentials which could be used for treatment against diarrhoea caused by Escherichia coli.

Authors' Contributions: OOL conceived and designed the research, performed data analysis and interpretation, and drafted the manuscript. OBM participated in data analysis and interpretation. IPA and FOC reviewed the draft manuscript for sound intellectual contents, while AO participated in data management. All the authors approved the final version of the manuscript.

Conflict of Interest: None.

Funding: Self-funded.

Publication History: Submitted 22 March 2021; Accepted 08 August 2021.

\section{References}

1. Madigan MT, Martinko JM, Parker J. Brook's Biology of Microbiology. 9th Edition, PrenticeHall International, London, UK. 2000: p. 504 507.

2. Steinkraus K. Handbook of Indigenous Fermented Foods. Marcel Dekker Inc., New York, USA. 1996: p. 4-16.

3. Adebolu TT, Olodun AO, Ihunweze BC. Evaluation of Ogi liquor from different grains for antibacterial activities against some common diarrhoeal bacteria in Southwest Nigeria. Afr J Biotechnol 2007; 6: 1140-1143.

4. Bulut C, Gunes H, Okuklu B, Harsa S, Killic S, Coban HS, et al. Homofermentative lactic acid bacteria of traditional cheese, Comleckpeyniri from Cappadocia region. J Dairy Res 2005; 72:19-24. https://doi.org/10.1017/s0022029904000536

5. Vrese M, Marteau PR. Effects of probiotics and prebiotics supplement on diarrhoea. Amer Soc Nutr 2007; 137: 803S-811S. https://doi.org/10.1093/jn/137.3.803S
6. David TK, Gerald EW. The National Series for Independent Study. 2nd Edition. Harwal Publishing. 1990.

7. Ohenhen RE, Ikenebomeh MJ. Shelf stability and enzyme activity studies of Ogi: A cornmeal fermented product. J Ann Sci 2007; 3: $38-42$.

8. Zhang YJ, Li S, Gan RY, Zhou T, Xu DP, Li HHB. Impacts of gut bacteria on human health and diseases. Int J Molecular Sci 2015; 16: 7493-7519.

https://doi.org/10.3390/ijms16047493

9. Savadogo A, Outtara Ca, Bassole IH, Traore SA. Bacteriocins and lactic acid bacteria- a mini-review. Afr J Biotechnol 2006; 5: 678-683. https://doi.org/10.5897/AJB05.388

10. Allart JK, Van Asten JA, Vernooi JC Grone A. Effect of Lactobacillus fermentum on beta 2 toxin production by Clostridium perfringens. Appl Environ Microb 2011; 77: 4406-4411. https://doi.org/10.1128/AEM.03002-10.

11. Hamad SH, Boecker G, Vogel RF, Hammes WP. Microbiological and chemical analysis of fermented sorghum dough for kisra production. Appl Microbiol 1992; 37: 728-731.

12. EUCAST. Breakpoint tables for interpretation of MICs and zone diameters. Breakpoint tables for interpretation of MICs and zone diameters. Version 5.0. European Committee on Antimicrobial susceptibility Testing. 2015.

13. Alshara M. Antimicrobial-resistant pattern of Escherichia coli strains isolated from paediatric patients in Jordan. Acta Med Iran 2011; 49: 293-295.

https://doi.org/10.1016/j.medmal.2009.06.0 $\underline{07}$

14. George-Okafor UO, Anosike EE. Fermented corn waste liquor as a potential source for probiotic lactic acid bacteria. Niger J Biotechnol 2011; 22: 17-22.

15. David OM, Famurewa O. Prophylactic and bio-therapeutic benefits of 'Ogi': A lactic acid fermented food. Researcher 2010; 2: 72-77.

16. Ojo OE, Sowemimo A, Ayeni FA. Evaluation of the viability of lactic acid bacteria in a 
Okunye OL, et al.

Nigerian commercial yoghurt. Afr J Food Nutr Res 2019; 3: 175-180.

17. Pal A, Ramana K. Purification and characterization of bacteriocin from Weissella paramesenteroides DFR-8, an isolate from cucumber (Cucumis sativus). J Food Biochem 2010; 34:

932-

948. 4514.2010.00340.x

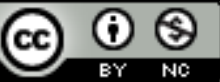

This is an Open Access document licensed for distribution under the terms and conditions of the Creative Commons Attribution License (http://creativecommons.org/licenses/by-nc/4.0). This permits unrestricted, non-commercial use, reproduction and distribution in any medium provided the original source is adequately cited and credited. 